\title{
Image-guided system versus manual marking for toric intraocular lens alignment in cataract surgery
}

Citation for published version (APA):

Webers, V. S. C., Bauer, N. J. C., Visser, N., Berendschot, T. T. J. M., van den Biggelaar, F. J. H. M., \& Nuijts, R. M. M. A. (2017). Image-guided system versus manual marking for toric intraocular lens alignment in cataract surgery. Journal of Cataract and Refractive Surgery, 43(6), 781-788. https://doi.org/10.1016/j.jcrs.2017.03.041

Document status and date:

Published: 01/06/2017

DOI:

10.1016/j.jcrs.2017.03.041

Document Version:

Publisher's PDF, also known as Version of record

Document license:

Taverne

Please check the document version of this publication:

- A submitted manuscript is the version of the article upon submission and before peer-review. There can be important differences between the submitted version and the official published version of record.

People interested in the research are advised to contact the author for the final version of the publication, or visit the DOI to the publisher's website.

- The final author version and the galley proof are versions of the publication after peer review.

- The final published version features the final layout of the paper including the volume, issue and page numbers.

Link to publication

\footnotetext{
General rights rights.

- You may freely distribute the URL identifying the publication in the public portal. please follow below link for the End User Agreement:

www.umlib.nl/taverne-license

Take down policy

If you believe that this document breaches copyright please contact us at:

repository@maastrichtuniversity.nl

providing details and we will investigate your claim.
}

Copyright and moral rights for the publications made accessible in the public portal are retained by the authors and/or other copyright owners and it is a condition of accessing publications that users recognise and abide by the legal requirements associated with these

- Users may download and print one copy of any publication from the public portal for the purpose of private study or research.

- You may not further distribute the material or use it for any profit-making activity or commercial gain

If the publication is distributed under the terms of Article $25 \mathrm{fa}$ of the Dutch Copyright Act, indicated by the "Taverne" license above, 


\title{
Image-guided system versus manual marking for toric intraocular lens alignment in cataract surgery
}

\author{
Valentijn S.C. Webers, MD, Noel J.C. Bauer, MD, PhD, Nienke Visser, MD, PhD, Tos T.J.M. Berendschot, PhD, \\ Frank J.H.M. van den Biggelaar, PhD, Rudy M.M.A. Nuijts, $M D, P h D$
}

Purpose: To compare the accuracy of toric intraocular lens (IOL) alignment using the Verion Image-Guided System versus a conventional manual ink-marking procedure.

Setting: University Eye Clinic Maastricht, Maastricht, the Netherlands.

Design: Prospective randomized clinical trial.

Methods: Eyes with regular corneal astigmatism of at least 1.25 diopters (D) that required cataract surgery and toric IOL implantation (Acrysof SN6AT3-T9) were randomly assigned to the image-guided group or the manual-marking group. The primary outcome was the alignment of the toric IOL based on preoperative images and images taken immediately after surgery. Secondary outcome measures were residual astigmatism, uncorrected distance visual acuity (UDVA), and complications.
Results: The study enrolled 36 eyes (24 patients). The mean toric IOL misalignment was significantly less in the image-guided group than in the manual group 1 hour (1.3 degrees \pm 1.6 [SD] versus $2.8 \pm 1.8$ degrees; $P=.02)$ and 3 months $(1.7 \pm 1.5$ degrees versus $3.1 \pm 2.1$ degrees; $P<.05)$ postoperatively. The mean residual refractive cylinder was $-0.36 \pm 0.32 D$ and $-0.47 \pm 0.28 D$ in the image-guided group and manual group, respectively $(P>.05)$. The mean UDVA was $0.03 \pm 0.10$ logarithm of minimum angle of resolution (logMAR) and $0.04 \pm 0.09 \log \mathrm{MAR}$, respectively (both $P>$.05). No intraoperative complications occurred during any surgery.

Conclusion: The IOL misalignment was significantly less with digital marking than with manual marking; this did not result in a better UDVA or lower residual refractive astigmatism.

J Cataract Refract Surg 2017; 43:781-788 ๔ 2017 ASCRS and ESCRS
$I^{\prime}$ $\mathrm{n}$ most patients who have cataract surgery, emmetropia can be achieved by correcting for refractive errors by implantation of a monofocal intraocular lens (IOL). However, approximately $20 \%$ to $30 \%$ of patients having cataract surgery have preexisting corneal astigmatism of 1.25 diopters (D) or more, which, when uncorrected during surgery, will result in spectacle dependency postoperatively. ${ }^{1-9}$ In patients without comorbidities and a desire to achieve postoperative freedom from spectacles for distance vision, the correction of astigmatism could be addressed at the time of surgery by using toric IOLs.

Numerous studies have shown that the implantation of a toric IOL is safe and effective. ${ }^{10,11}$ After toric IOL implantation, $70 \%$ to $85 \%$ of all patients are spectacle-independent for distance visual acuity. ${ }^{10,12-17}$ One factor that determines the effectiveness of the astigmatism correction is the accuracy of toric IOL alignment; every 5 degrees of misalignment will decrease the anticipated effect by $17 \%{ }^{18-20}$ Therefore, accurate alignment of the toric IOL is essential to achieve excellent postoperative outcomes and reduce residual refractive astigmatism.

Since the introduction of the toric IOL, many manual marking techniques have been used for the alignment of toric IOLs. ${ }^{20-25}$ However, with a recently introduced digital marking system (Verion Digital Marker M, Alcon Laboratories, Inc.) toric IOLs can be aligned without preoperative manual marking.

The purpose of this study was to compare the accuracy of a new digital marking technique with a conventional manual marking technique for toric IOL alignment.

\section{PATIENTS AND METHODS}

In this randomized controlled trial, patients with cataract and concomitant corneal astigmatism were recruited from the 
Maastricht University Eye Clinic. All patients provided informed consent. The study was performed in compliance with the tenets of the Declaration of Helsinki and good clinical practice guidelines and was registered in a clinical trial register. ${ }^{\mathrm{A}}$ Approval of an investigational review board was obtained before the start of this study.

The main inclusion criteria were unilateral or bilateral preexisting corneal astigmatism of $1.25 \mathrm{D}$ or more and age of 18 years or older. Exclusion criteria were irregular corneal astigmatism, previous intraocular or corneal surgery, Fuchs endothelial dystrophy (stage 2 or higher), extensive age-related macular degeneration, glaucoma or diabetic macular disease, or other contraindications to cataract surgery and toric IOL implantation.

\section{Toric Intraocular Lens Selection and Calculation}

In all cases, an Acrysof aspheric toric IOL (model SN6AT3-9, Alcon Laboratories, Inc.) with cylindrical powers in $0.75 \mathrm{D}$ steps ranging from $1.50 \mathrm{D}$ (T3) to $6.00 \mathrm{D}$ (T9) and spherical powers ranging from +6.00 to $+30.00 \mathrm{D}$ was implanted. To calculate the spherical power of the toric IOL, optical biometry (Carl Zeiss Meditec AG) and the Sanders-Retzlaff-Kraff formula ${ }^{26}$ (SRK/T, A-constant 118.9) were used. The cylindrical power of the toric IOL was determined by transferring into an online toric calculator ${ }^{\mathrm{B}}$ the keratometry reading obtained by an optical biometer based on partial coherence interferometry (PCI) (IOLMaster, Carl Zeiss Meditec AG). The web-based toric calculator takes into account mandatory data input, such as the expected surgically induced astigmatism (SIA) and the position of the main corneal incision. The expected SIA was $0.30 \mathrm{D}$ for a $2.2 \mathrm{~mm}$ superior incision. ${ }^{27}$

\section{Surgical Technique}

All surgeries in this study were performed by 1 of 2 experienced surgeons (R.N., N.B.). The surgical technique, except the method of marking for toric IOL alignment, was standardized in each patient. In all cases, a standard divide-and-conquer phacoemulsification technique was performed through a superior $2.2 \mathrm{~mm}$ clear corneal incision.

The manual marking technique consisted of a 3-step procedure. After the eye was marked at 0 degree, 180 degrees, and 270 degrees using the Nuijts-Lane preoperative toric reference corneal marker (AE-2793S, Asico LLC), with the patient seated, the desired implantation axis was marked intraoperatively using a Mendez ring and a Nuijts toric axis marker (AE-2740, Asico LLC). Implantation and alignment of the toric IOL were performed until the IOL marks were in line with the manually placed ink alignment marks.

The Verion Image-Guided System, which consists of a measurement module and digital marker, was used to perform digital marking for toric IOL alignment. Preoperatively, a highresolution color reference image of the patient's eye was obtained using the measurement module. These images were transferred to the digital marker. Using multiple reference points on the conjunctiva and limbus, a digital overlay of the imported preoperative image and live-surgery image was created. Because of the eyetracking navigation of the system, cyclotorsion and eye movements are eliminated, allowing the desired implantation axis of the toric IOL to be accurately projected in the right ocular of the surgeon's microscope.

\section{Randomization}

Consecutive patients were randomly assigned to have digital marking or manual marking. Blocked randomization was performed to reduce bias and achieve balance in the allocation of participants to both treatment arms. The assigned randomization was e-mailed to the surgeon 1 day before surgery. The patient and investigator performing the postoperative examinations were masked to the treatment allocation. At the 3-month follow-up, the randomization was revealed.

\section{Preoperative Assessment}

Preoperatively, each patient had a full ophthalmologic evaluation using slitlamp biomicroscopy, including fundoscopy and intraocular pressure measurement. Automated keratometry (PCI-based and the image-guided system's reference unit) and corneal topography (Pentacam, Oculus Optikgeräte $\mathrm{GmbH}$ ) were performed before surgery.

\section{Determination of Misalignment and Rotation Stability}

At all postoperative visits (1 hour, 1 week, 1 month, and 3 months), slitlamp photography in full mydriasis (phenylephrine hydrochloride $100 \mathrm{mg} / \mathrm{mL}$, tropicamide $5 \mathrm{mg} / \mathrm{mL}$ ) was performed. All slitlamp photographs were examined by the same researcher (V.W.). Misalignment was defined as the difference between the desired toric IOL axis and the achieved axis 1 hour postoperatively. To eliminate cyclotorsion or an in-habitual head position, the postoperatively obtained slitlamp photographs were compared with preoperative images obtained with the image-guided system's measurement unit; these images were obtained while the patient's eyes were in a horizontal position. The preoperative image-guided system measurements were performed according to the manufacturer's directions. These include having patients place their chin in the center of the chinrest and affirming constant contact of the forehead with the horizontal supporting band. In addition, head tilt was prevented during the measurements by ensuring that an imaginary line connecting the outer canthi was running parallel with the supporting band.

Reference spots on the conjunctiva and limbus were marked in the preoperative images and postoperative images using Photoshop CS6 (version 13.01.3, Adobe Systems, Inc.). After an overlay of both images was created by matching all reference spots, the achieved toric IOL axis was determined using its marks, thereby excluding changes in eye or head position.

A comparable technique was used to determine rotation stability postoperatively. Rotation was defined as the difference between the implanted toric IOL axis 1 hour postoperatively and the toric IOL axis at consecutive follow-up visits. The rotation of the toric IOLs was determined using Adobe Photoshop CS6 and the horizontal reference markings obtained from the preoperative image (as described above).

\section{Visual and Refractive Outcomes}

At each follow-up visit, monocular uncorrected distance visual acuity (UDVA) and corrected distance visual acuity (CDVA) were measured using Early Treatment Diabetic Retinopathy Study charts at $4 \mathrm{~m}$. Patients were asked to start reading the charts at the smallest row on which all letters were easily distinguishable. $\mathrm{Pa}$ tients were asked to continue to read rows with smaller letters until no letters on a row were read correctly. The correct number of letters was noted and transferred into logarithm of minimum angle of resolution $(\log$ MAR) values for use in the analyses.

\section{Sample Size}

A sample-size calculation was performed using an $\alpha$ of 0.05 and a power of $80 \%$. A previous study examining manual eye marking ${ }^{22}$ found a mean toric IOL misalignment of 5.0 degrees \pm 2.1 (SD) in pseudophakic eyes. In a pilot study, ${ }^{\mathrm{C}}$ the mean misalignment of the image-guided system was 2.5 degrees. Based on these assumptions and assuming a dropout of $15 \%$ on the primary outcome measure, the study would have to include a minimum of 36 eyes.

\section{Statistical Analysis}

All data were collected in an electronic data-capture system for medical research (Castor EDC, CIWIT B.V., Amsterdam) and transferred to SPSS for Windows software (version 23.0, 2010, International Business Machines Corp.) for data analysis. An intention-to-treat analysis was performed. Differences in 
alignment between groups were analyzed using the independent Student $t$ test. If the distribution of variables was not normal, the nonparametric Wilcoxon rank-sum test was used. Paired $t$ tests were used to analyze the changes in visual acuities and residual refractive cylinder between preoperative visits and postoperative visits. Vector analysis according to the Alpin method ${ }^{28}$ was used to translate corneal and refractive astigmatism into Cartesian coordinates $(x$ and $y$ ). In all tests, a threshold of statistical significance was assumed equal to a $P$ value of 0.05 .

\section{RESULTS}

Thirty-six eyes were randomly assigned to the manual group or the image-guided group (Figure 1). The imageguided group comprised 18 eyes of 17 patients ( 9 women [50\%]) with a mean age of 68 years (range 23 to 89 years). The manual group comprised 18 eyes of 17 patients (6 women [33\%]) with a mean age of 70 years (range 23 to 89 years). Preoperatively, there were no statistically significant differences in age, sex distribution, refractive, and anterior or posterior corneal astigmatism between the 2 groups (Table 1). A statistically significant difference was noted in preoperative CDVA favoring the imageguided group (Table 1). One patient in the image-guided group was lost to follow-up as a result of a systemic health disorder. Intraoperative digital marking failed in 1 patient, resulting in conversion to an intraoperative manual marking technique.

\section{Misalignment}

Table 2 shows the mean misalignment 1 hour postoperatively in both groups. Of the 36 anterior segment slitlamp photographs, 35 could be used for analysis of misalignment 1 hour postoperatively. Misalignment was significantly lower in the image-guided group than in the manual group $(P=.02)$. The misalignment ranged from 0.0 to 6.1 degrees in the image-guided group and from 0.3 to 6.5 degrees in the manual group. Postoperative toric IOL misalignment of 5 degrees or less occurred in 17 patients $(94 \%)$ in the image-guided group and 14 patients (81\%) in the manual group. Counterclockwise rotation compared with the desired implantation axis was seen in 10 patients (57\%) in the image-guided group and in 11 patients (64\%) in the manual group.

\section{Rotational Stability}

Table 2 shows the mean rotation of the toric IOLs measured at consecutive follow-up visits. In 27 of 36 cases, anterior slitlamp photographs of good quality were obtained at all 4 follow-up visits. The mean rotation during the followup period (1 hour to 3 months) was comparable between the 2 groups $(P=.25)$. In terms of rotation over time (1 hour to 3 months), a statistically significant decrease in rotation was measured ( $P=.04$, image-guided group; $P=.03$, manual group); however, no statistically significant differences were seen between the 2 groups at any of follow-up timepoint $(P=.13, P=.71$, and $P=.25$ for 1 week, 1 month, and 3 months, respectively). The percentage of clockwise rotation during follow-up was $78 \%$ (14 patients) in the image-guided group and $82 \%$ (14 patients) in the manual group. Three months postoperatively, the mean error in alignment (misalignment and rotation combined) was significantly less in the image-guided group than in the manual group $(P=.05)$.

\section{Visual Acuity and Refraction}

Three months postoperatively, the mean UDVA was $0.03 \pm 0.10 \operatorname{logMAR}$ in the image-guided group and $0.04 \pm 0.09 \operatorname{logMAR}$ in the manual group $(P=.74)$. The mean CDVA was $-0.05 \pm 0.08 \log$ MAR and $-0.04 \pm$ $0.07 \log$ MAR, respectively $(P=.82)$.

A statistically significant reduction between preoperative corneal astigmatism and postoperative refractive astigmatism occurred in both groups (both $P<.0001$ ) (Figure 2). The mean residual refractive astigmatism 3 months postoperatively was $-0.36 \pm 0.32 \mathrm{D}$ in the

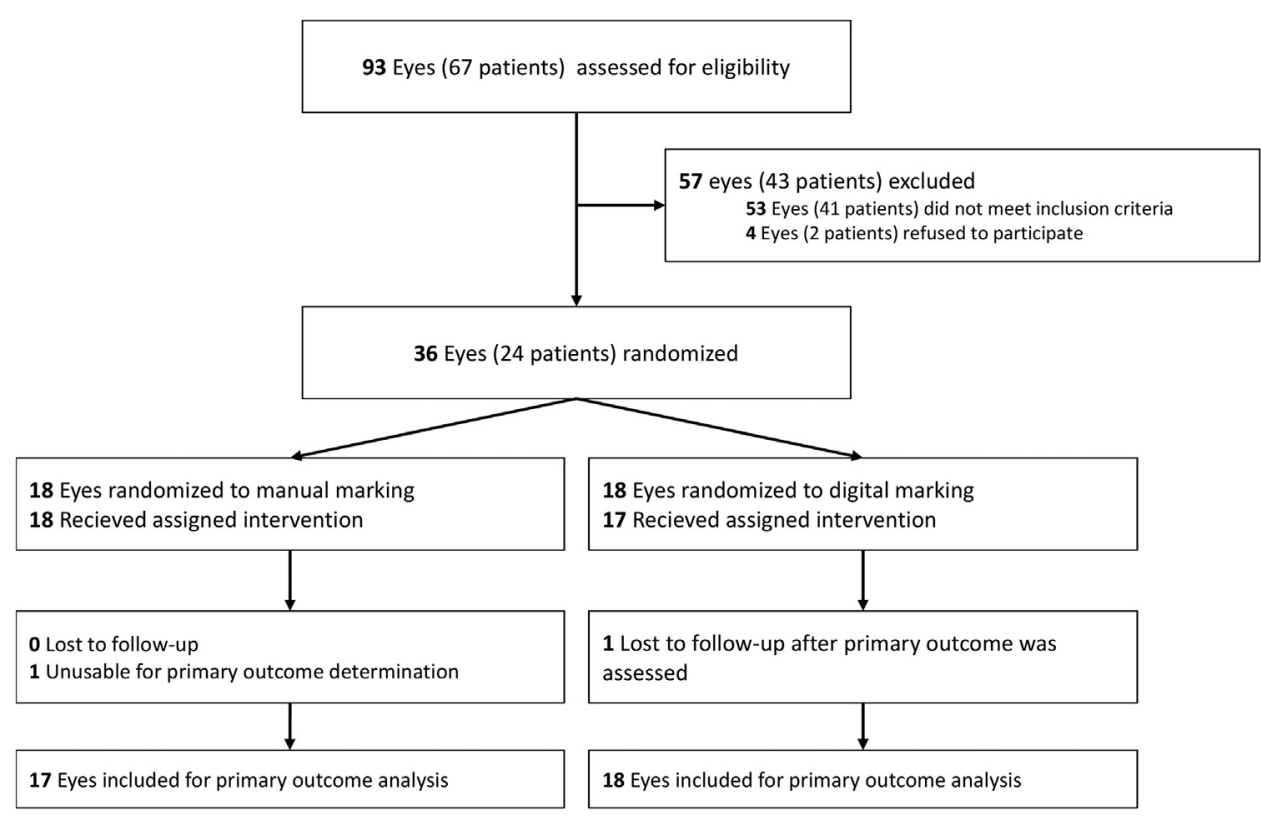

Figure 1. Patient screening and follow-up. 


\begin{tabular}{|c|c|c|c|c|}
\hline \multirow[b]{2}{*}{ Characteristic } & \multicolumn{2}{|c|}{ Image-Guided Group } & \multicolumn{2}{|c|}{ Manual Group } \\
\hline & Mean \pm SD & Range & Mean \pm SD & Range \\
\hline CDVA (logMAR) & $0.10 \pm 0.10^{*}$ & $-0.06,0.26$ & $0.24 \pm 0.21^{*}$ & $0.04,0.92$ \\
\hline Refractive astigmatism (D) & $-2.15 \pm 1.04$ & $-1.00,-4.75$ & $-2.47 \pm 1.17$ & $-1.00,-6.00$ \\
\hline Keratometric corneal astigmatism (D) & $2.29 \pm 0.90$ & $1.32,5.08$ & $2.42 \pm 0.95$ & $1.54,5.23$ \\
\hline $\begin{array}{l}\text { Topographic corneal astigmatism (D) } \\
\text { Anterior } \\
\text { Posterior }\end{array}$ & $\begin{array}{l}2.12 \pm 0.90 \\
0.40 \pm 0.25\end{array}$ & $\begin{array}{c}1.20,4.80 \\
0.0,0.9\end{array}$ & $\begin{array}{l}2.19 \pm 0.91 \\
0.41 \pm 0.25\end{array}$ & $\begin{array}{c}1.20,4.80 \\
0.0,0.1\end{array}$ \\
\hline
\end{tabular}

CDVA $=$ corrected distance visual acuity.

${ }^{\star} P<.05$.

image-guided group, representing a reduction of $84 \%$ of the preexisting astigmatism magnitude, and $-0.47 \pm 0.28 \mathrm{D}$ in the manual group, representing a reduction of $81 \%$ of the preexisting astigmatism magnitude. Three months postoperatively, the mean SIA was $-0.27 \pm 0.44 @ 113$ in the image-guided group and $-0.21 \pm 0.51 @ 121$ in the manual group. The mean magnitude of SIA was $0.64 \pm 0.38 \mathrm{D}$ and $0.58 \pm 0.33 \mathrm{D}$, respectively. Twentyone patients $(60 \%)$ had a magnitude of SIA greater than $0.50 \mathrm{D}$.

Figure 3 shows the distribution of UDVA and residual refractive astigmatism in both groups 3 months postoperatively. There were no statistically significant differences in terms of UDVA, CDVA, or mean residual refractive astigmatism between the 2 groups at any time during the followup $(P>.05)$.

\section{Vector Analysis}

Table 3 shows the astigmatism parameters 3 months postoperatively obtained through vector analyses. No statistically significant differences were seen in the correction index, index of success, magnitude of error, or angle of error between the 2 groups $(P>.05)$. The mean correction index in the image-guided group was slightly higher than in the manual group $(P=.18)$ (Figure 4$)$, representing a general

\begin{tabular}{|c|c|c|}
\hline \multirow[b]{2}{*}{ Postop Parameter } & \multicolumn{2}{|c|}{ Mean \pm SD } \\
\hline & $\begin{array}{l}\text { Image-Guided } \\
\text { Group }\end{array}$ & Manual Group \\
\hline $\begin{array}{l}\text { Misalignment }\left({ }^{\circ}\right) \\
1 \text { hour }\end{array}$ & $1.3 \pm 1.6^{*}$ & $2.8 \pm 1.8^{*}$ \\
\hline $\begin{array}{l}\text { Absolute rotation } \\
\text { over time }\left({ }^{\circ}\right) \\
1 \text { hour-1 week } \\
1 \text { hour-1 month } \\
1 \text { hour-3 months }\end{array}$ & $\begin{array}{l}0.5 \pm 0.6 \\
1.1 \pm 1.0 \\
1.1 \pm 1.0\end{array}$ & $\begin{array}{l}1.1 \pm 1.1 \\
1.2 \pm 1.0 \\
1.5 \pm 1.1\end{array}$ \\
\hline $\begin{array}{l}\text { Absolute diff between } \\
\text { intended vs achieved } \\
\text { axis }\left(^{\circ}\right) \\
1 \text { hour } \\
1 \text { week } \\
1 \text { month } \\
3 \text { months }\end{array}$ & $\begin{array}{l}1.3 \pm 1.6^{\star} \\
1.1 \pm 1.6^{\star} \\
1.7 \pm 1.4^{\star} \\
1.7 \pm 1.5^{\star}\end{array}$ & $\begin{array}{l}2.8 \pm 1.8^{*} \\
2.8 \pm 2.0^{*} \\
3.1 \pm 2.2^{\star} \\
3.1 \pm 2.1^{\star}\end{array}$ \\
\hline
\end{tabular}

diff $=$ difference

${ }^{\star} P<.05$ overcorrection in both groups. In the image-guided group, 9 patients (53\%) had an overcorrection of $0.25 \mathrm{D}$ or more and 5 patients $(29 \%)$ had $0.50 \mathrm{D}$ or more. In the manual group, the overcorrection was $0.25 \mathrm{D}$ or more in 7 patients (39\%) and $0.50 \mathrm{D}$ or more in 4 patients (22\%). The success of astigmatism correction was $73 \%$ in the image-guided group and $78 \%$ in the manual group $(P>.05)$.
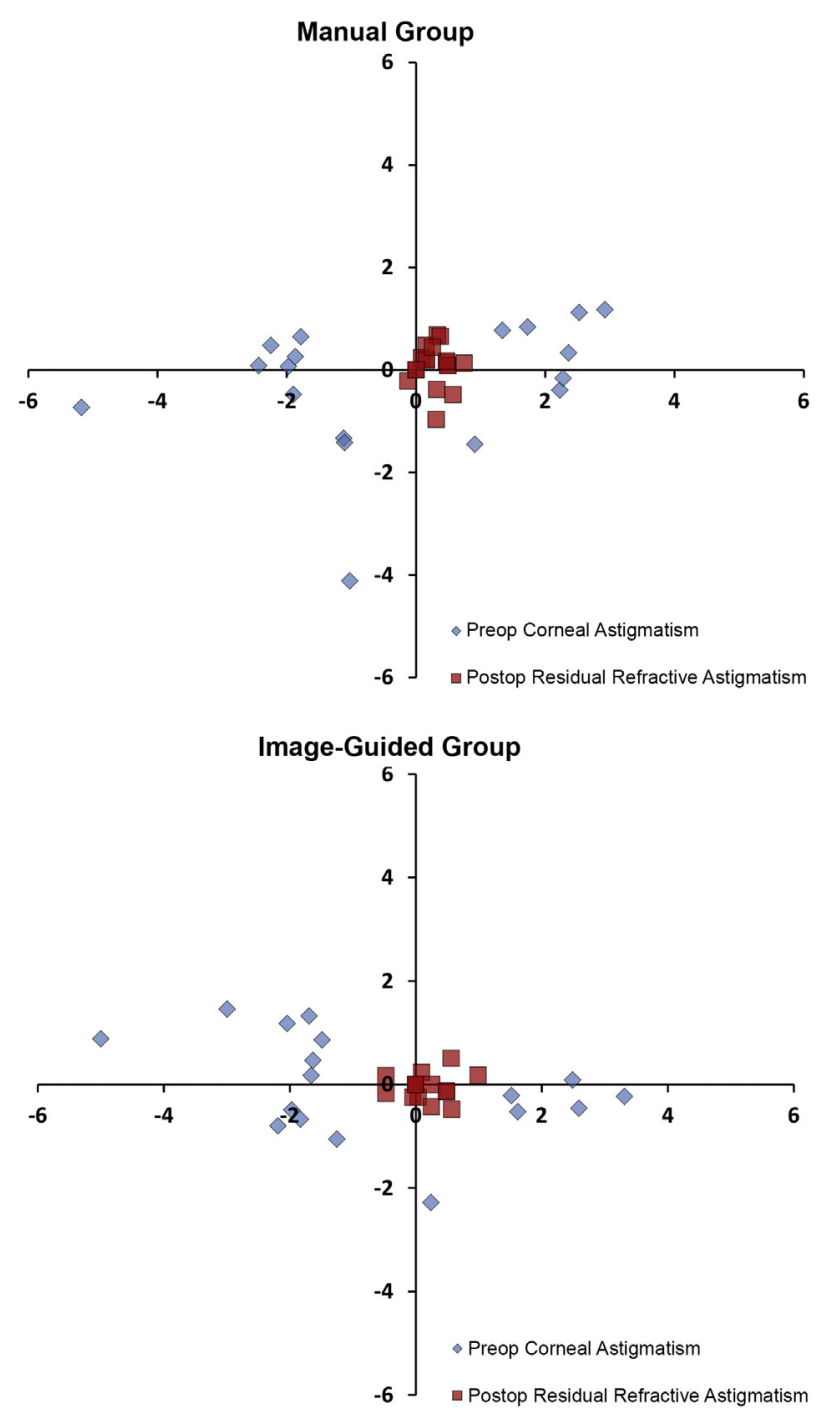

Figure 2. Double-angle vector plot comparing preoperative corneal astigmatism and postoperative residual refractive astigmatism. Values are in diopters. 


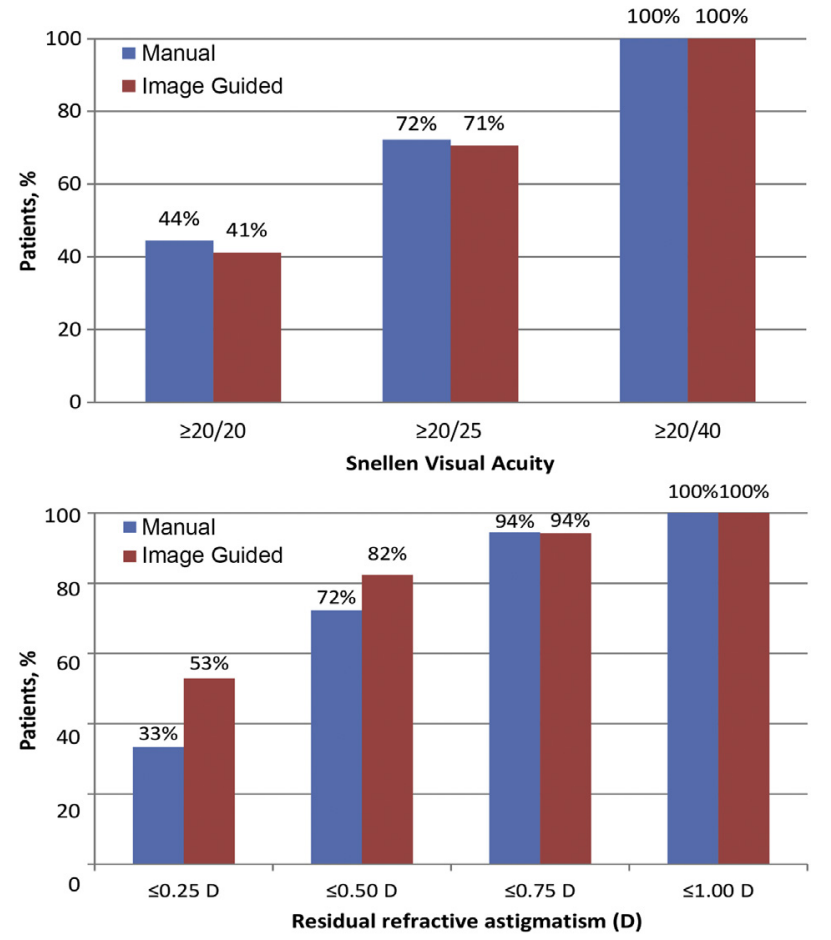

Figure 3. Cumulative postoperative monocular UDVA (top) and residual refractive astigmatism (bottom) 3 months postoperatively.

\section{Complications and Adverse Events}

No complications occurred during any surgery. Postoperatively, a macular pucker was seen in 1 patient in the manual group. Neodymium:YAG laser capsulotomy was performed
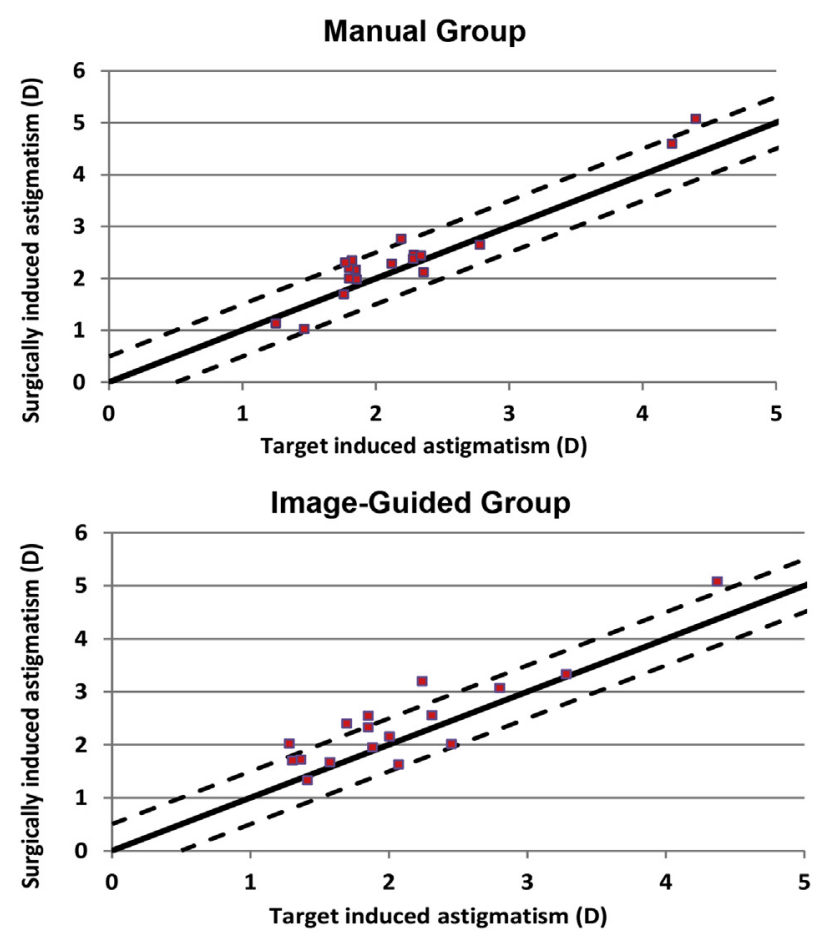

Figure 4. Target-induced astigmatism (TIA) versus SIA of the preexisting corneal astigmatism 3 months after surgery. Ideally, the ratio between SIA and TIA is 1.0. An overcorrection reflects in a ratio higher than 1.0, whereas an undercorrection results in a ratio lower than 1.0 .
Table 3. Alpins vector analysis ${ }^{28}$ of the effectiveness of astigmatism correction using toric IOLs.

\begin{tabular}{|l|c|c|}
\hline \multirow{2}{*}{ Parameter } & \multicolumn{2}{|c|}{ Mean \pm SD } \\
\cline { 2 - 3 } & $\begin{array}{c}\text { Image-Guided } \\
\text { Group }\end{array}$ & Manual Group \\
\hline Target induced astigmatism (D) & $2.10 \pm 0.80$ & $2.24 \pm 0.83$ \\
\hline $\begin{array}{l}\text { Total surgically induced } \\
\text { astigmatism (D) }\end{array}$ & $2.39 \pm 0.90$ & $2.42 \pm 0.99$ \\
\hline Difference vector (D) & $0.51 \pm 0.29$ & $0.46 \pm 0.27$ \\
\hline Magnitude of error (D) & $0.29 \pm 0.40$ & $0.18 \pm 0.31$ \\
\hline Angle of error $\left({ }^{\circ}\right)$ & $-2 \pm 16$ & $-6 \pm 14$ \\
\hline Absolute angle of error $\left({ }^{\circ}\right)$ & $11 \pm 12$ & $9 \pm 11$ \\
\hline Correction index* & 1.16 & 1.07 \\
\hline Index of success & 0.27 & 0.22 \\
\hline
\end{tabular}

*Mean only

in 1 eye in both groups to treat posterior capsule opacification. No toric IOL had to be repositioned.

\section{DISCUSSION}

The purpose of this study was to compare the accuracy of a new digital marking technique with a commonly used manual marking procedure in the alignment of toric IOLs during cataract surgery. Using slitlamp photography, the misalignment 1 hour after surgery was determined. In our study, there was a significant difference in misalignment between the groups favoring the Verion image-guided system over the manual marking procedure. However, the difference in misalignment did not result in significant differences in UDVA or residual refractive astigmatism between the 2 groups 3 months postoperatively.

Sources of residual refractive astigmatism after toric IOL implantation include variations in SIA, the effects of posterior astigmatism, and misalignment of the toric IOL. A reduction of $3.3 \%$ in astigmatism correction for every degree of misalignment of the toric IOL axis to its desired axis reflects the importance of perfect intraoperative alignment and excellent postoperative rotation stability. Developments in toric IOL design and material and marking techniques for toric IOL alignment have resulted in improved outcomes after toric IOL implantation for the correction of preexisting corneal astigmatism. ${ }^{29-34}$

Various methods to mark the eye before toric IOL implantation have been described; of them, manual marking is considered the gold standard at present. In a study by Visser et al., ${ }^{22}$ the use of a 3-step ink-marker procedure led to a mean error in alignment of $4.9 \pm 2.1$ degrees. Popp et al. ${ }^{24}$ compared several manual methods for marking the eye (slitlamp, pendulum, bubble-marker, and tonometer). The mean errors in toric IOL alignment ranged from $1.8 \pm 2.2$ degrees (pendulum) to $4.7 \pm 2.9$ degrees (tonometer), indicating that the pendulum method achieved the highest accuracy.

Several studies evaluated other approaches, such as eye mapping, using a corneal analyzer system and using a 3dimension (3-D) imaging system. Cha et al. ${ }^{23}$ compared 3 methods; that is, marking the eye with a toric reference marker, using the slit beam, and using a mapping method. 
The mapping method consisted of preoperatively obtained slitlamp photography to identify several reference vessel points. During surgery, these reference points were used to mark the desired toric IOL axis using calipers. To evaluate the accuracy of the 3 axis-marking methods, anterior segment photographs were taken. This new mapping method led to statistically significant smaller error in marking the eye than when conventional marking methods were used $(2.3 \pm 1.1$ degrees versus $3.7 \pm 1.5$ degrees versus $3.1 \pm 1.6$ degrees) (all $P<.05$ ). Carey et al. ${ }^{21}$ analyzed postoperative misalignment after manual intraoperative marking using a 4-point procedure. After the eye was marked at 12 o'clock and 6 o'clock using a Codman surgical pen, the slit beam was rotated 90 degrees to mark the eye at 9 o'clock and 3 o'clock. The 3 -month postoperative misalignment was measured using 2 techniques, a slitlamp approach and a corneal analyzer. Both methods showed a high correlation and comparable means of misalignment $(2.7 \pm 2.0$ degrees versus $2.6 \pm 2.8$ degrees for corneal analyzer and slitlamp approach, respectively) $(r=0.99, P<.001)$. Montes de Oca et al..$^{25}$ analyzed the accuracy of toric IOL axis alignment using a 3-D computer-guided visualization system compared with the accuracy of a manual marking procedure to mark the eye at 0 degree and 180 degrees. The digital method used a preoperative high-resolution photograph and intraoperative registration of the patient's eye based on scleral and limbal vessels to allow digital surgical guidance and alignment of the toric IOL. The mean error of $3.0 \pm 2.5$ degrees and $2.9 \pm 2.2$ degrees in the digital group and manual group, respectively, was not significantly different between the 2 methods.

Table 4 shows an overview of the findings in previous studies, reflecting a wide range in misalignment between different marking methods. In the current study, significantly less misalignment immediately after surgery was

\begin{tabular}{|c|c|}
\hline Study & Mean Misalignment $\left({ }^{\circ}\right)$ \\
\hline $\begin{array}{l}\text { Visser }^{22} \\
\text { Bubble marker }\end{array}$ & $4.9 \pm 2.1$ \\
\hline $\begin{array}{l}\text { Popp } \\
\text { Slitlamp } \\
\text { Pendulum } \\
\text { Bubble marker } \\
\text { Tonometer }\end{array}$ & $\begin{array}{l}2.3 \pm 1.8 \\
1.8 \pm 2.2 \\
2.9 \pm 1.9 \\
4.7 \pm 2.9\end{array}$ \\
\hline $\begin{array}{l}\text { Cha }^{23} \\
\text { Reference marker } \\
\text { Slitlamp } \\
\text { Mapping method }\end{array}$ & $\begin{array}{l}3.7 \pm 1.5 \\
3.1 \pm 1.6 \\
2.3 \pm 1.1\end{array}$ \\
\hline $\begin{array}{l}\text { Carey }^{21} \\
\text { Slitlamp } \\
\text { Corneal analyzer }\end{array}$ & $\begin{array}{l}2.6 \pm 2.8 \\
2.7 \pm 2.0\end{array}$ \\
\hline $\begin{array}{l}\text { Montes de Oca }{ }^{25} \\
\text { Reference marker } \\
\text { 3-D imaging }\end{array}$ & $\begin{array}{l}2.9 \pm 2.2 \\
3.0 \pm 2.5\end{array}$ \\
\hline $\begin{array}{l}\text { Current } \\
\text { Reference marker } \\
\text { Image-guided system }\end{array}$ & $\begin{array}{l}2.8 \pm 1.8 \\
1.3 \pm 1.6\end{array}$ \\
\hline
\end{tabular}

*First author seen with the image-guided system than with the manual marking procedure. The findings in the manual group are comparable to those seen in previous studies. However, the mean misalignment in the image-guided group was less than that reported in previous studies of manual marking, indicating the former is more accurate than other manual marking methods. However, there are limitations to comparing previously published studies ${ }^{21-25}$ and the current study. In many of these studies, postoperative misalignment was not measured immediately after surgery but rather several weeks later. It is well known that toric IOLs can rotate in the early postoperative period. ${ }^{35}$ Therefore, measuring misalignment after a few weeks can distort the true misalignment because of the possible rotation of the IOL. Furthermore, most studies used a slitlamp orientation to determine misalignment, while we created an overlay between preoperative images and postoperative images to eliminate cyclotorsion and differences in the patient's head position.

At 3 months, $82 \%$ in the image-guided group and $72 \%$ in the manual group achieved a postoperative residual refractive cylinder of $0.50 \mathrm{D}$ or less. This appears to be a higher proportion than in most recent studies, in which residual astigmatism of $0.50 \mathrm{D}$ or less occurred in approximately $50 \%$ of cases. ${ }^{11,33}$ In our study, there were no statistically significant differences in terms of the mean UDVA and mean residual refractive astigmatism between the 2 groups. However, 3 months postoperatively the mean error in alignment (misalignment and rotation combined) was significantly less in the image-guided group than in the manual marking group $(1.7 \pm 1.5$ degrees and $3.1 \pm 2.1$ degrees, respectively) $(P=.05)$. These findings could be explained by different causes. First, although the difference in misalignment immediately after surgery between the 2 groups was significant, it was rather small (ie, 1.5 degrees). This difference in alignment remained stable during the 3 months of follow-up. At 3 months, the mean absolute difference between the intended axis and the achieved axis was $1.7 \pm 1.5$ degrees in the image-guided group and $3.1 \pm 2.1$ degrees in the manual group $(P<.05)$. In the current study the mean preoperative corneal astigmatism was relatively low $(2.42 \pm 0.95 \mathrm{D}$ and $2.29 \pm 0.90 \mathrm{D}$, respectively). Therefore, the impact of a 1.5-degree difference in alignment error might not be clinically relevant in this population. However, this difference might become clinically relevant in patients with a higher level of preexisting corneal astigmatism. Second, in the current study, we used a first-generation toric calculator. ${ }^{\mathrm{B}}$ This calculator does not take posterior corneal astigmatism and effective lens position (ELP) into account.

It is well known that posterior astigmatism plays an important role in the calculation of cylindrical power of a toric IOL. ${ }^{36-41}$ Because the posterior side of the cornea acts as a minus lens, neglecting this part of the cornea will result in overcorrection of the preexisting corneal astigmatism in a patient with with-the-rule astigmatism, whereas an undercorrection will occur in patients with against-the-rule astigmatism. In the current study, a mean 
overcorrection occurred in both groups (1.16 D and 1.07 D in image-guided group and manual group, respectively) $(P=.18)$. The higher amount of overcorrection in the image-guided group might be explained by the lower misalignment 3 months postoperatively. The cylindrical power of the toric IOL calculated by a toric calculator that uses input from anterior keratometry and neglects posterior astigmatism was on average $0.40 \mathrm{D}$ and $0.41 \mathrm{D}$ in the image-guided group and manual group, respectively, and will usually result in overcorrection. Because of the higher misalignment in the manual group, a reduction of the anticipated correction of the preexisting corneal astigmatism resulted in less overcorrection than in the image-guided group. Therefore, it is essential in the near future to implement second-generation toric calculators that take posterior astigmatism and ELP into account to prevent residual refractive astigmatism in cases in which the toric IOL is or nearly is perfectly aligned. 38,42

In conclusion, both the digital and manual marking methods showed high accuracy in aligning toric IOLs intraoperatively. Although this study did not show significant advantages in terms of UDVA and residual refractive astigmatism using the digital marking system, IOL misalignment was significantly less in this group than in the manual marking procedure. Further studies will be required to determine whether the current difference might be more clinically relevant in a patient population with higher levels of preexisting corneal astigmatism. Future studies should also assess the effect on residual refractive astigmatism of updated toric calculators that account for posterior astigmatism in combination with digital marking technology.

\section{WHAT WAS KNOWN}

- Adequate alignment of toric IOLs is essential to achieve excellent postoperative results.

\section{WHAT THIS PAPER ADDS}

- The new digital approach that uses eye-tracking navigation to eliminate cyclotorsion and eye movements reduced misalignment immediately after surgery by $50 \%$ compared with a commonly used 3-step manual marking procedure.

\section{REFERENCES}

1. Attebo K, Ivers RQ, Mitchell P. Refractive errors in an older population; the Blue Mountains Eye Study. Ophthalmology 1999; 106:1066-1072

2. The Eye Diseases Prevalence Research Group. The prevalence of refractive errors among adults in the United States, Western Europe, and Australia. Arch Ophthalmol 2004; 122:495-505. Erratum 2005; 123:1314. Article Available at: http://jamanetwork.com/journals/ jamaophthalmology/fullarticle/416214. Erratum Available at: http://archo pht.jamanetwork.com/article.aspx?articleid=417292. Accessed April 12, 2017

3. Vitale S, Cotch MF, Sperduto RD. Prevalence of visual impairment in the United States. JAMA 2006; 295:2158-2163. Available at: http:// jamanetwork.com/journals/jama/fullarticle/202836. Accessed April 12, 2017

4. Vitale S, Ellwein L, Cotch MF, Ferris FL III, Sperduto R. Prevalence of refractive error in the United States, 1999-2004. Arch Ophthalmol
2008; 126:1111-1119. Available at: http://jamanetwork.com/journals/ jamaophthalmology/fullarticle/420707. Accessed April 12, 2017

5. Hoffmann PC, Hütz WW. Analysis of biometry and prevalence data for corneal astigmatism in 23,239 eyes. J Cataract Refract Surg 2010; 36:1479-1485

6. Kim EC, Morgan IG, Kakizaki H, Kang S, Jee D. Prevalence and risk factors for refractive errors: Korean National Health and Nutrition Examination Survey 2008-2011. PloS One 2013; 8:e80361. Available at: https://www.ncbi. nlm.nih.gov/pmc/articles/PMC3818255/pdf/pone.0080361.pdf. Accessed April 12, 2017

7. Mohammadi M, Naderan M, Pahlevani R, Jahanrad A. Prevalence of corneal astigmatism before cataract surgery. Int Ophthalmol 2016; 36:807-817

8. Williams KM, Verhoeven VJM, Cumberland P, Bertelsen G, Wolfram C, Buitendijk GHS, Hofman A, van Duijn CM, Vingerling JR, Kuijpers RWAM, Höhn R, Mirshahi A, Khawaja AP, Luben RN, Erke MG, von Hanno T, Mahroo O, Hogg R, Gieger C, Cougnard-Grégoire A, Anastasopoulos E, Bron A, Dartigues J-F, Korobelnik J-F, Creuzot-Garcher C, Topouzis F, Delcourt C, Rahi J, Meitinger T, Fletcher A, Foster PJ, Pfeiffer N, Klaver CCW, Hammond CJ. Prevalence of refractive error in Europe: the European Eye Epidemiology $\left(E^{3}\right)$ Consortium. Eur J Epidemiol 2015; 30:305-315. Available at: https://www.ncbi.nlm.nih.gov/pmc/articles/ PMC4385146/pdf/10654_2015_Article_10.pdf. Accessed April 12, 2017

9. Collier Wakefield O, Annoh R, Nanavaty MA. Relationship between age, corneal astigmatism, and ocular dimensions with reference to astigmatism in eyes undergoing routine cataract surgery. Eye 2016; 30:562-569. Available at: https:/www.ncbi.nlm.nih.gov/pmc/articles/PMC5108535/pdf/ eye2015274a.pdf. Accessed April 12, 2017

10. Visser N, Beckers HJM, Bauer NJC, Gast STJM, Zijlmans BLM, Berenschot TTJM, Webers CA, Nuijts RMMA. Toric vs aspherical control intraocular lenses in patients with cataract and corneal astigmatism; a randomized clinical trial. JAMA Ophthalmol 2014; 132:1462-1468. Available at: http://jamanetwork.com/journals/jamaophthalmology/fullarticle/1906175. Accessed April 12, 2017

11. Kessel L, Andresen J, Tendal B, Erngaard D, Flesner P, Hjortdal J. Toric intraocular lenses in the correction of astigmatism during cataract surgery; a systematic review and meta-analysis. Ophthalmology 2016; 123:275286. Available at: http://www.aaojournal.org/article/S0161-6420(15)011483/pdf. Accesssed April 12, 2017

12. Lane SS, Ernest P, Miller KM, Hileman KS, Harris B, Waycaster CR. Comparison of clinical and patient-reported outcomes with bilateral AcrySof toric or spherical control intraocular lenses. J Refract Surg 2009; 25:899-901

13. Mingo-Botốn D, Muñoz-Negrete FJ, Kim HRW, Morcillo-Laiz R, Rebolleda G, Oblanca N. Comparison of toric intraocular lenses and peripheral corneal relaxing incisions to treat astigmatism during cataract surgery. J Cataract Refract Surg 2010; 36:1700-1708

14. Ahmed IIK, Rocha G, Slomovic AR, Climenhaga H, Gohill J, Grégoire A, Ma J, for the Canadian Toric Study Group. Visual function and patient experience after bilateral implantation of toric intraocular lenses. J Cataract Refract Surg 2010; 36:609-616

15. Holland E, Lane S, Horn JD, Ernest P, Arleo R, Miller KM. The AcrySof toric intraocular lens in subjects with cataracts and corneal astigmatism; a randomized, subject-masked, parallel-group, 1-year study. Ophthalmology 2010; 117:2104-2111

16. Zhang J-S, Zhao J-Y, Sun Q, Ma L-W. Distance vision after bilateral implantation of AcrySof toric intraocular lenses: a randomized, controlled, prospective trial. Int J Ophthalmol 2011; 4:175-178. Available at: http:// www.ncbi.nlm.nih.gov/pmc/articles/PMC3340696/pdf/ijo-04-02-175.pdf. Accessed April 12, 2017

17. Waltz KL, Featherstone K, Tsai L, Trentacost D. Clinical outcomes of TECNIS toric intraocular lens implantation after cataract removal in patients with corneal astigmatism. Ophthalmology 2015; 122:39-47

18. Novis C. Astigmatism and toric intraocular lenses. Curr Opin Ophthalmol 2000; 11:47-50

19. Viestenz A, Seitz B, Langenbucher A. Evaluating the eye's rotational stability during standard photography; effect on determining the axial orientation of toric intraocular lenses. J Cataract Refract Surg 2005; 31:557-561

20. Ma JJK, Tseng SS. Simple method for accurate alignment in toric phakic and aphakic intraocular lens implantation. J Cataract Refract Surg 2008; 34:1631-1636

21. Carey PJ, Leccisotti A, McGilligan VE, Goodall EA, Moore CBT. Assessment of toric intraocular lens alignment by a refractive power/corneal analyzer system and slitlamp observation. J Cataract Refract Surg 2010; 36:222-229

22. Visser $\mathrm{N}$, Berendschot $\Pi J \mathrm{M}$, Bauer NJC, Jurich J, Kersting $\mathrm{O}$, Nuijts RMMA. Accuracy of toric intraocular lens implantation in cataract and refractive surgery. J Cataract Refract Surg 2011; 37:1394-1402 
23. Cha D, Kang SY, Kim S-H, Song J-S, Kim H-M. New axis-marking method for a toric intraocular lens: mapping method. J Refract Surg 2011; 27:375-379

24. Popp N, Hirnschall N, Maedel S, Findl O. Evaluation of 4 corneal astigmatic marking methods. J Cataract Refract Surg 2012; 38:2094-2099

25. Montes de Oca I, Kim EJ, Wang L, Weikert MP, Khandelwal SS, Al-Mohtaseb Z, Koch DD. Accuracy of toric intraocular lens axis alignment using a 3-dimensional computer-guided visualization system. J Cataract Refract Surg 2016; 42:550-555

26. Retzlaff JA, Sanders DR, Kraff MC. Development of the SRK/T intraocular lens implant power calculation formula. J Cataract Refract Surg 1990; 16:333-340; erratum, 528

27. Visser N, Berendschot TTJM, Bauer NJC, Nuijts RMMA. Vector analysis of corneal and refractive astigmatism changes following toric pseudophakic and toric phakic IOL implantation. Invest Ophthalmol Vis Sci 2012; 53:1865-1873. Available at: http://iovs.arvojournals.org/article.aspx? articleid=2188106. Accessed April 12, 2017

28. Alpins N. Astigmatism analysis by the Alpins method. J Cataract Refract Surg 2001; 27:31-49

29. Patel CK, Ormonde S, Rosen PH, Bron AJ. Postoperative intraocular lens rotation; a randomized comparison of plate and loop haptic implants. Ophthalmology 1999; 106:2190-2195; discussion by DJ Apple, 2196

30. Linnola RJ, Werner L, Pandey SK, Escobar-Gomez M, Znoiko SL, Apple DJ. Adhesion of fibronectin, vitronectin, laminin, and collagen type IV to intraocular lens materials in pseudophakic human autopsy eyes. Part 1: histological sections. J Cataract Refract Surg 2000; 26:1792-1806

31. Chang DF. Early rotational stability of the longer Staar toric intraocular lens; fifty consecutive cases. J Cataract Refract Surg 2003; 29:935-940

32. Lombardo M, Carbone G, Lombardo G, De Santo MP, Barberi R. Analysis of intraocular lens surface adhesiveness by atomic force microscopy. J Cataract Refract Surg 2009; 35:1266-1272

33. Visser N, Bauer NJC, Nuijts RMMA. Toric intraocular lenses: historical overview, patient selection, IOL calculation, surgical techniques, clinical outcomes, and complications. J Cataract Refract Surg 2013; 39:624-637

34. Thulasi P, Khandelwal SS, Randleman JB. Intraocular lens alignment methods. Curr Opin Ophthalmol 2016; 27:65-75

35. Miyake T, Kamiya K, Amano R, lida Y, Tsunehiro S, Shimizu K. Long-term clinical outcomes of toric intraocular lens implantation in cataract cases with preexisting astigmatism. J Cataract Refract Surg 2014; 40:1654-1660

36. Koch DD, Jenkins RB, Weikert MP, Yeu E, Wang L. Correcting astigmatism with toric intraocular lenses: effect of posterior corneal astigmatism. J Cataract Refract Surg 2013; 39:1803-1809

37. Abulafia A, Barrett GD, Kleinmann G, Ofir S, Levy A, Marcovich AL, Michaeli A, Koch DD, Wang L, Assia El. Prediction of refractive outcomes with toric intraocular lens implantation. J Cataract Refract Surg 2015; 41:936-944
38. Abulafia A, Hill WE, Franchina M, Barrett GD. Comparison of methods to predict residual astigmatism after intraocular lens implantation. J Refract Surg 2015; 31:699-707

39. Zhang L, Sy ME, Mai H, Yu F, Hamilton DR. Effect of posterior corneal astigmatism on refractive outcomes after toric intraocular lens implantation. J Cataract Refract Surg 2015; 41:84-89

40. Eom Y, Rhim JW, Kang S-Y, Kim S-W, Song JS, Kim HM. Toric intraocular lens calculations using ratio of anterior to posterior corneal cylinder power. Am J Ophthalmol 2015; 160:717-724

41. Koch DD. The enigmatic cornea and intraocular lens calculations: the LXXIII Edward Jackson Memorial Lecture. Am J Ophthalmol 2016; 171:xV-XXX. Available at: http://www.ajo.com/article/S0002-9394(16)30404-4/pdf. Accessed April 12, 2017

42. Abulafia A, Koch DD, Wang L, Hill WE, Assia El, Franchina M, Barrett GD. New regression formula for toric intraocular lens calculations. J Cataract Refract Surg 2016; 42:663-671

\section{OTHER CITED MATERIAL}

A. U.S. National Institutes of Health Clinical Trials. VERION Versus Conventional, Manual Ink-Marking in Toric IOL Implantation. NCT02370953. Available at: https://clinicaltrials.gov/ct2/show/NCT02370953. Accessed April 12, 2017

B. Alcon Surgical, Inc. AcrySof ${ }^{\circledR}$ Toric IOL Web Based Calculators, version 3.2.2.

C. Webers VSC, Bauer NJC, Visser N, Berendschot TTJM, van den Biggelaar FJHM, Nuijts RMMA (unpublished data)

Disclosures: Dr. Nuijts is a consultant to Alcon Laboratories, Inc., Asico LLC, and Théa Pharma GmbH. He receives financial support for research from Alcon Laboratories, Inc., Bausch \& Lomb, Inc., Gebauer Medizintechnik GmbH, Humanoptics AG, Ophtec BV, and Physiol S.A. and receives lecture fees from Alcon Laboratories, Inc. Dr. Bauer is a consultant to and receives lecture fees from Alcon Laboratories, Inc. and Bausch \& Lomb, Inc. He receives financial support for research from Alcon Laboratories, Inc. and Physiol S.A. None of the other authors has a financial or proprietary interest in any material or method mentioned.

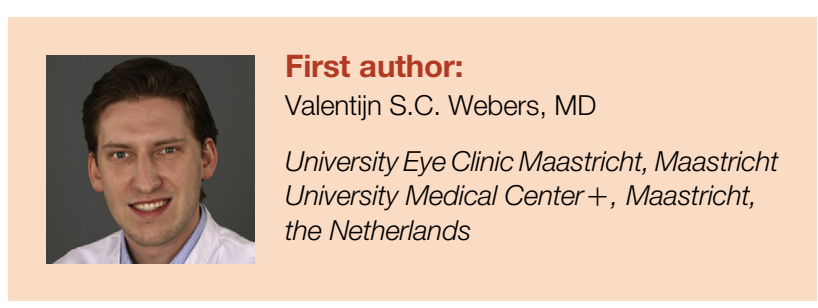

